\title{
Effects of Annealing on Deformation Textures in Galena
}

\author{
Bruce R. Clark, Floyd R. Price, and William C. Kelly \\ Department of Geology and Mineralogy, The University of Michigan, \\ Ann Arbor, Michigan, 48109, U.S.A.
}

\begin{abstract}
Experimental annealing of galena samples with known deformation histories shows that this mineral has the necessary properties to be a valuable source of information about low-grade deformational environments. Annealed galena displays recovery and/or recrystallization features dependent upon the type of texture inherited from the tectonic event, which in turn is closely linked to deformation temperatures.

In samples deformed at temperatures less than $200^{\circ} \mathrm{C}$ in the laboratory, later annealing produced subgrains, mosaics of new grains, or rapid grain boundary migration as the annealing temperatures were varied from $200^{\circ} \mathrm{C}$ to $700^{\circ} \mathrm{C}$. Kink bands maintained characteristic straight simple boundaries inherited from the deformation event. Samples deformed above $300^{\circ} \mathrm{C}$ developed "syntectonically" recrystallized textures. Kink bands had been converted to elongate grains with complex sutured grain boundaries during deformation, and mosaics of new grains were found in highly deformed regions. These textures were extremely stable through later annealing. Despite our changing annealing temperatures through $500^{\circ} \mathrm{C}$, we did not produce similar textures from both low and high temperature deformation runs.

Examination of polished and etched galena from low-grade tectonic settings may well be worth the effort since galena textures appear to display features indicative of deformational evironments, even after being subjected to considerable post-tectonic thermal perturbations.
\end{abstract}

\section{Introduction}

The development of microscopic textures in tectonites has been the subject of extensive investigation in the laboratory in the past 20 years (see review by Carter, 1976). One elusive target of this research has been to correlate interactions among the processes of deformation, recovery, and recrystallization. This is a particularly difficult problem to attack in the laboratory for most of the common rock-forming minerals because of their sluggish reaction rates and the need to anneal them at temperatures so high that intermediate stages are 
bypassed. However, interesting results were reported by Griggs et al. (1960) and Hobbs (1968), so the authors carried out a series of annealing experiments on samples of a very reactive mineral, galena, which had been previously deformed experimentally under a variety of pressure-temperature conditions.

The experimental deformation of galena (Salmon et al., 1974) showed that its texture was responding to the temperature at which it was deformed. At temperatures above about $100^{\circ} \mathrm{C}$, the galena samples showed evidence of recovery, and above $200^{\circ} \mathrm{C}$, true recrystallization, during deformation. In view of the variety of "syntectonic" modifications that could be induced in the laboratory, we expected annealing to be a reasonably dynamic process, and it was.

Galena textures can play an integral role in unraveling the tectonic history of deformed ore deposits in low-grade metamorphic settings, and they have the potential for greater use in general tectonic studies as well. For example, recent evidence (Stanton and Willey, 1972; Salmon et al., 1974) suggests that schistose galena, such as that from Coeur d'Alene, Idaho, is a recrystallized deformation texture. In the present study we have attempted to place limits on possible tectonic environments in which such a texture could form.

The galena annealed in this study had been deformed experimentally at temperatures of $25^{\circ}$ to $500^{\circ} \mathrm{C}$ and confining pressures of 50 to $200 \mathrm{MPa}$ (Salmon et al., 1974), and the entire deformation/annealing history is accurately known. Undeformed galena from the Southeast Missouri lead district was the original material. The samples were polished and etched and in many cases the same features were photographed both before and after the annealing experiments.

\section{Terminology}

The authors follow the terminology reviewed by Cahn (1971):

Annealing is a heat-treating process under no external stress, intended to reduce or eliminate deformation-induced crystallographic damage.

Recovery applies to the internal crystallographic changes which do not involve migration of high angle grain boundaries. It is usually accompanied by decreases in dislocation density, Vickers hardness, resistivity, and yield stress. The texture may form subgrains, segments of original grains that are slightly misoriented with respect to each other. Subgrain boundaries are commonly networks of dislocations which migrated to those sites during recovery. Recovery implies that dislocation climb is possible, so that dislocations can move out of their glide planes and bypass other crystal defects.

Recrystallization is the migration of high angle grain boundaries.

Primary recrystallization involves the "nucleation" and growth of grains at the expense of previously deformed material, although "nucleation" is still poorly understood.

Secondary recrystallization describes coarsening or further enlargement of some recrystallized grains at the expense of others.

Syntectonic recrystallization refers to recrystallization which accompanies deformation. For the galena samples studied here, "syntectonic" recrystallizatin occurred in the laboratory.

\section{Previous Studies}

Previous investigations of annealing in galena involve experimental annealing of naturally deformed galena (Siemes, 1964; Stanton and Gorman, 1968, 1970, 
1972), syntectonic annealing during experimental deformation (Salmon et al., 1974; Atkinson, 1974, 1976a, b) and experimental annealing of samples experimentally deformed at room temperature (Lyall and Paterson, 1966; Siemes, 1976). A general pattern of recovery and recrystallization has been recognized from these studies by means of X-ray back reflection photographs, microhardness indentation measurements, optical measurement of triple junction angles, and some optical identification of features such as mosaics of equidimensional grains suggesting primary recrystallization.

In this paper, we present the optical evidence for a range of recovery and recrystallization behavior in galena. We have worked with samples deformed at temperatures from $24-500^{\circ} \mathrm{C}$ and annealed from $200-700^{\circ} \mathrm{C}$. We have limited our analysis to microscopic observations based on the beliefs that the microscopic features may be even more sensitive to the deformation/annealing history than microhardness or X-ray measurements, and that microscopic criteria are certain to be more commonly used.

\section{Evolution of Textural Features}

This study was particularly concerned with the effects that a previous deformation history would have on the course of recrystallization. The galena annealed under static conditions during the present research, had been deformed experimentally under known conditions. Previous deformation experiments (Salmon et al., 1974) produced a variety of features visible in the polished and etched galena, including a) kink bands and curved $\{001\}$ cleavages indicating residual distorted crystal lattices, b) local high concentrations of etch pits indicating high dislocation densities, c) opened cleavage fractures, and d) some zones of pervasive cataclasis. The specific features formed were a function of the pressure-temperature conditions under which the galena was deformed.

Recrystallization began "syntectonically" during the higher temperature experiments. The degree of "syntectonic" recrystallization that occurred had a significant effect on the types of textures that evolved during the later static annealing runs. Consequently, in this section, we shall first review the original textures and those produced during deformation, then discuss the results of the annealing experiments.

\section{Undeformed Textures}

The initial starting materials were described in detail by Salmon et al. (1974). The ore is a coarse-grained $(1-10 \mathrm{~mm})$ galena with low porosity $(<2 \%)$ and fewer than $10 \%$ impurities. Grain boundaries are irregular, often jagged, and triple junction boundaries are far from equilibrium. A distinct substructure characterized by incomplete subgrain boundaries in the larger grains is characteristic of the undeformed galena. This generation of subgrains is referred to as original subgrains and apparently results from the normal distortions inevitable when growing such large grains in nature. The average diameter of the subgrains 

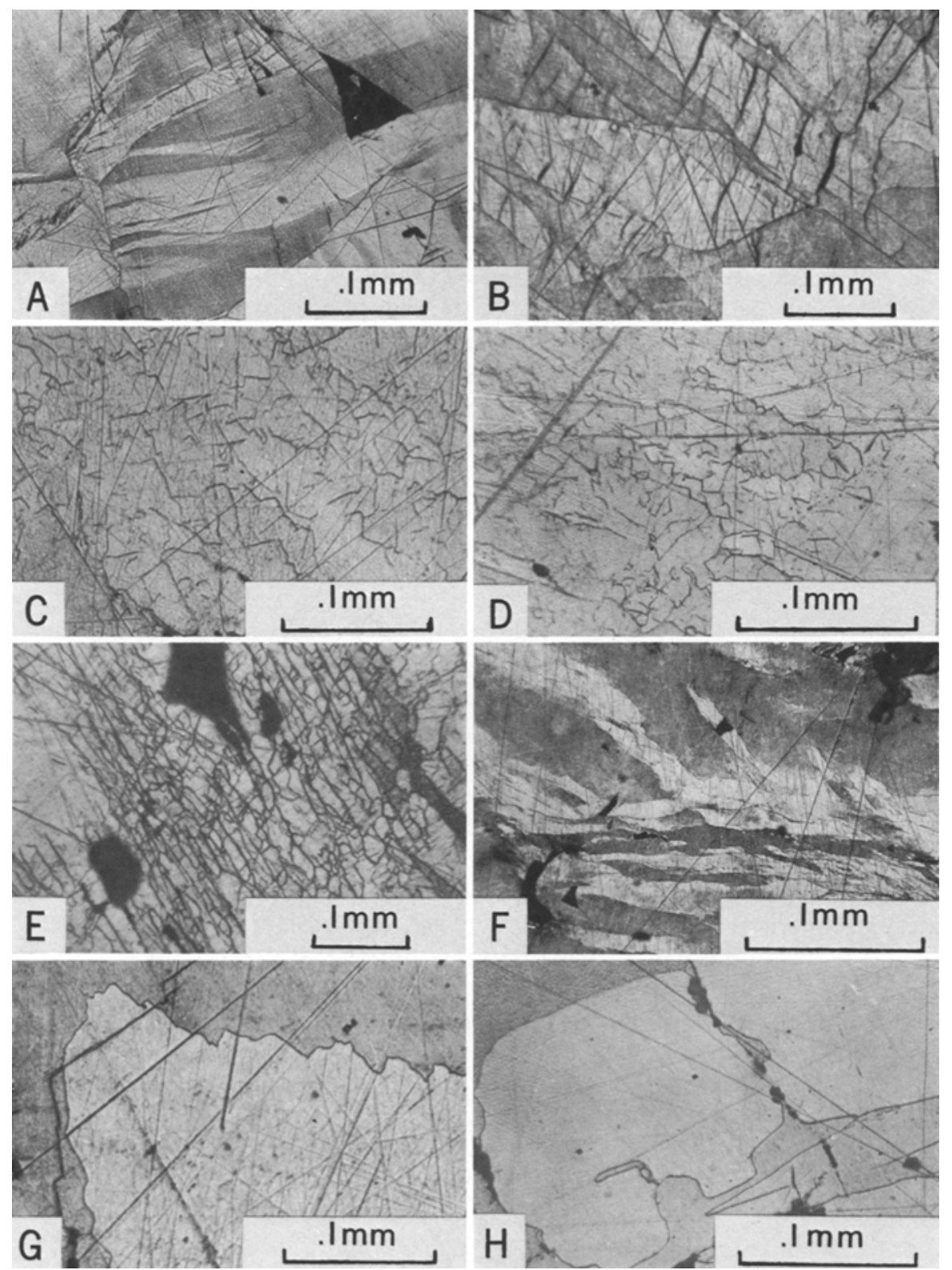

Fig. $1 \mathrm{~A}-\mathrm{H}$. Reflected light photomicrographs of polished and etched galena aggregates. Numbers after description give total shortening in \%/deformation temperature. A Kink bands with diffuse and sharp boundaries in galena deformed at low temperature. Curvature of crystal is shown by curved edge of cleavage pit (upper right). $13 \% / 24^{\circ} \mathrm{C}$. B Open cleavage cracks (NE-SW) preferentially located in kink bands. Kink boundaries are generally sharp and simple. $26 \% / 24^{\circ} \mathrm{C}$. C Incipient secondary subgrains formed during deformation at moderate temperature. Note that many subboundaries remain incomplete and most are not controlled by cleavage. $12 \% / 200^{\circ} \mathrm{C}$. D Incipient secondary subgrains formed during annealing at moderate temperature following low temperature deformation. These subgrains are indistinguishable from those formed during deformation. 12\%/ 
is approximately $0.5 \mathrm{~mm}$. Within a subgrain, the cleavages are rarely curved enough to be seen optically, but distinct deflection can be seen in cleavage orientations when the cleavage crosses a subgrain boundary.

\section{Effects of Deformation}

Deformation of samples at $24^{\circ}$ and $100^{\circ} \mathrm{C}$ produced no evidence of either recovery or recrystallization features. Original subgrains are still present but no new ones are apparent. Evidence of deformation is abundant: open fractures following cleavages, curved cleavages indicating distorted crystal structures, and distinct kink bands with both sharp and broad boundaries (Figs. $1 \mathrm{~A}$ and $\mathrm{B}$ ).

In samples deformed at $200^{\circ} \mathrm{C}$ a new generation of secondary subgrains appeared (Fig. 1C). These subgrains are an order of magnitude smaller than original subgrains and tend to form first as clusters in highly deformed segments of grains. Kink bands appear to have sharp rather than broad boundaries. The optical evidence points to a "syntectonic" recovery process active even in the short time that the sample was at temperature. However, most grain boundaries remain unequilibrated, and curved cleavages still abound.

At a deformation temperature of $300^{\circ} \mathrm{C}$, secondary subgrain boundaries are more clear and completely formed. The kink boundaries have become sharp, sutured elongate grain boundaries (Fig. 1F), indicating that true recrystallization has occurred locally. The original grain boundaries are still clear and are commonly followed by fractures. In many grains cleavages are still curved and it is clear that recovery and recrystallization have not been complete.

At $400^{\circ} \mathrm{C}$, subgrains become increasingly difficult to find, and in their place is a new texture consisting of a fine mosaic of small recrystallized grains with an average grain size somewhat larger than that of the missing subgrains. The new grains etch to a similar degree, but boundaries between them are very sharp and strongly etched. Some curved cleavages and rare examples of broad indistinct kink boundaries remain locally.

After deformation at $500^{\circ} \mathrm{C}$, the mosaic of new fine grains is well developed over much of the sample. All the "kink bands" are now elongate grains with sharp sutured boundaries. Some rapid grain boundary migration occurred in these samples even though they were held at temperature for less than $2 \mathrm{~h}$.

A variety of recrystallization features was thus already present prior to the annealing runs. The abundance of features was a function of the amount

$100^{\circ} \mathrm{C}$; annealed 50 days $/ 200^{\circ} \mathrm{C} . \mathrm{E}$ New grain mosaic thought to develop from secondary subgrains during later annealing. Grain boundaries well formed; etch intensity varies, indicating variations in orientation. $25 \% / 400^{\circ} \mathrm{C}$; annealed 40 days $/ 400^{\circ} \mathrm{C}$. F Kink bands converted to elongate grains during deformation at high temperature. Boundaries are sutured and complex, often contain small new grains along them. $25 \% / 300^{\circ} \mathrm{C}$. G Beginnings of rapid grain boundary migration in galena deformed at high temperature. Sample was rapidly heated, held at temperature only 1.5 hours. $13 \% / 500^{\circ} \mathrm{C}$. H Rapid grain boundary migration during high temperature annealing of low temperature deformation run. Large light colored grain was actively growing but grain boundaries appear pinned locally. $25 \% / 24^{\circ} \mathrm{C}$; annealed 30 days $/ 500^{\circ} \mathrm{C}$ 
of deformation of the sample, but the appearance of a particular feature was controlled largely by the temperature at which the sample was deformed.

\section{Effects of Annealing}

The major results of the annealing experiments are illustrated in "before" and "after" photographs of particular features in Figure 2, and are summarized in Figures 3-6. In general, the "degree" of recrystallization experienced by a sample was dependent upon the temperature and the length of time the sample was annealed. However, the graphs clearly show that at least some features owed their appearance, even in the final annealed texture, to the temperature of deformation (Figs. 4, 6).

The rates of annealing generally followed a sigmoidal pattern with time (Beck, 1954; Stanton, 1972). In our annealing experiments, the rate of formation of strain-free material (either recrystallized grains or mosaics of subgrains) within the strained matrix progressed in three qualitative stages. At the beginning of the experiments the formation of strain-free material proceeded slowly. This was followed first by a tremendous increase in formation rate, and finally by a decrease in activity. The actual time required for each stage depended on the annealing temperature, as well as both the original deformation temperature and the total amount of strain. At $200^{\circ} \mathrm{C}$ annealing temperatures, the process was not complete after 50 days, whereas at $700^{\circ} \mathrm{C}$ annealing temperatures most of the very active recrystallization was completed in the first 6 days.

Three specific textural features are particularly noteworthy in the annealed samples: 1) the formation of elongate grains, 2) the evolution of mosaics of new grains from secondary subgrains, and 3) the onset of rapid grain boundary migration.

Elongate Grains. The galena samples deformed at low temperatures $\left(<200^{\circ} \mathrm{C}\right.$ ) display abundant kink bands with broad to sharp, straight boundaries (Fig. $2 \mathrm{~A}$ ). During the annealing experiments the kink bands tended to become discrete elongate grains with boundaries that closely coincided with the original kink band boundaries (Figs. 2B, 3). The elongate grains commonly maintain length: width ratios as large as $10: 1$. In our experiments they were an order of magnitude smaller than the original grains of the ore. In a few examples we were able to follow the evolution of a specific kink, but in general, the location of the original kink band boundary was evident from 1) bending of preexisting cleavage cracks, and 2) the location of families of open cleavage fractures produced in a single kink band.

Galena samples deformed at high temperatures $\left(>200^{\circ} \mathrm{C}\right)$ tended to form the elongate grains during the deformation event itself (Fig. 2C). However, these grains, also localized at kink bands, have sutured grain boundaries that distinguish them from the simple kink band boundaries in low temperature runs (Fig. 4). Annealing had very little effect on these apparently fully recovered grains (Fig. 2D). 


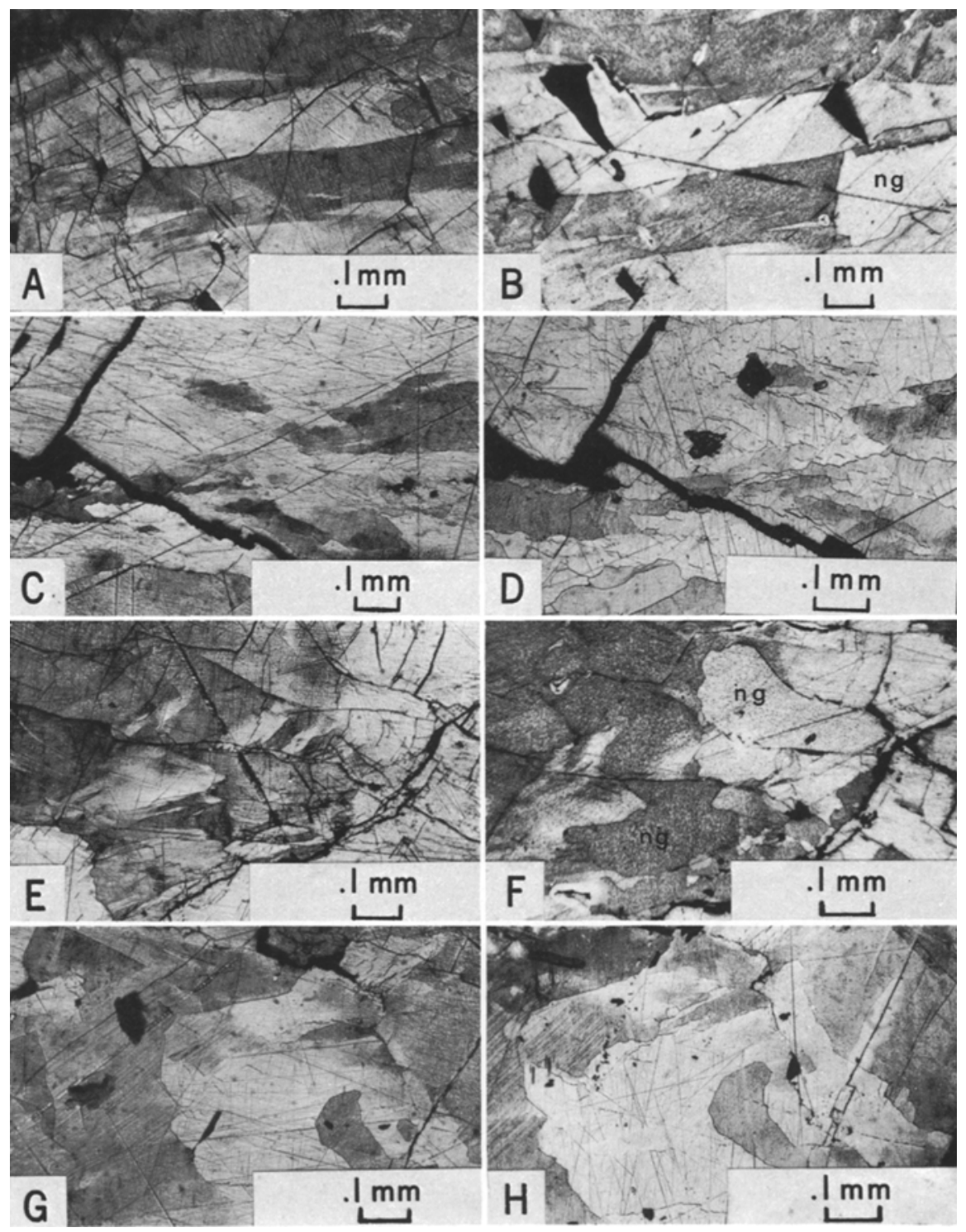

Fig. 2A-H. Reflected light photomicrographs showing BEFORE ANNEALING (left) and AFTER ANNEALING (right) views of the same areas. Samples were lightly polished and re-etched before the AFTER pictures were taken. Thus the right picture is from a slightly greater depth in section than left picture. $n g=$ new grain. A and B Straight simple kink band boundaries sharpened, but not sutured in later annealing event. Note new grain growing (right center) in annealed photo. Sample deformed $25 \%$ at $100^{\circ} \mathrm{C}$ (A), then annealed 30 days at $500^{\circ} \mathbf{C}$. (B). C and D sutured elongate grains formed "syntectionally" during deformation, relatively unaffected by later annealing. Sample deformed $13 \%$ at $400^{\circ} \mathrm{C}$ (C), then annealed 30 days at $500^{\circ} \mathrm{C}$ (D). $\mathbf{E}$ and $\mathbf{F}$ Highly strained kinked zone in low temperature run subjected to extensive rapid grain boundary migration during annealing. Sample deformed $25 \%$ at $100^{\circ} \mathrm{C}(\mathbf{E})$, then annealed 30 days at $500^{\circ} \mathrm{C}(\mathbf{F})$, $\mathbf{G}$ and $\mathbf{H}$ View from high temperature deformation run which experienced virtually no further recrystallization during further annealing. Sample deformed $13 \%$ at $400^{\circ} \mathrm{C}(\mathbf{G})$, then annealed 30 days at $500^{\circ} \mathrm{C}(\mathbf{H})$ 
It was assumed that annealing of the low temperature runs would also produce sutured elongate grains, and this was suggested by Stanton and Willey (1972) for the origin of the Coeur d'Alene galena texture. However, the effect of annealing our low temperature deformed specimens was simply to sharpen the kink band boundaries (Fig. 3) and produce elongate grains that retained the simple straight boundary geometry (Fig. 2B; 4). Our experiments suggest that the elongate grains will eventually be destroyed by excessive grain boundary migration, but that prior to that the character of elongate grains might be used successfully to differentiate between low $\left(<200^{\circ} \mathrm{C}\right.$ in the laboratory) and high $\left(>200^{\circ} \mathrm{C}\right)$ temperature conditions when the original deformation took place.

Subgrain and New Grain Mosaics. A second important textural adjustment during annealing is the formation of mosaics of very fine deformation-related subgrains (Fig. 1D), which appear to have rotated individually to form mosaics of new equidimensional grains as the annealing temperature was raised (Fig. 1E). A similar evolution of new grains from subgrains might also be expected if annealing could be extended to more geologically realistic lengths of time. Subgrains were distinguished from true grains on the basis of the similar depth of etching on adjacent individuals and the very faint etching of subboundaries. The subgrains grew both "syntectonically" in samples deformed at high temperatures and during annealing of samples deformed at low temperatures. We are not able to distinguish between these two subgroups in polished sections (Figs. 1C, D) so we refer to both as secondary subgrains in contrast to the "original" subgrains present in the starting material. When the individuals in a mosaic etch to noticeably different degrees and boundaries are clearly continuous and deeply etched, the term new grain mosaic is used. Such a distinction is admittedly tenuous, but efforts to refine the terms using transmission electron microscopy were not successful.

The rate of formation of secondary subgrains during annealing was dependent upon annealing temperature. Large numbers of subgrains appeared in similar samples after 10 days annealing at $200^{\circ} \mathrm{C}, 4$ days at $300^{\circ} \mathrm{C}$, and only two days at $400^{\circ} \mathrm{C}$. The subgrains formed characteristically at locations where high residual stresses might be expected: at grain and kink band boundaries, and around inclusions and cleavage fractures. Some kink bands within a single sample were completely replaced by subgrains while adjacent bands in the same set formed single elongate grains. This evidence is all compatible with the hypothesis that the secondary subgrains form in response to local attempts by the grain to reduce any accumulated strain energy during or after deformation.

Discontinuous subgrain boundaries are visible in Figures $1 \mathrm{C}$ and $\mathrm{D}$. In some cases dislocation etch pits could be seen following straight lines approaching a subgrain boundary where they made a slight but sharp bend. In the region beyond the terminated subboundary, the rows of etch pits were gently curved with no hint of a sharp bend.

The subgrain mosaics appear to grade into mosaics of new grains as the degree of annealing increases (Fig. 5). New grains tend to be considerably more misoriented with respect to adjacent grains, and to have much sharper, clearer 
Fig. 3. Sharpness of kink band/elongate grain boundaries as a function of deformation and annealing temperatures. The kink band boundaries are sensitive to both variables and show a definite tendency to become sharper at higher temperature as expected from classical recovery theory

Fig. 4. Complexity of kink band/elongate grain boundaries as a function of deformation and annealing temperatures. Elongate grains evolve from kink bands, but the initial deformation temperature strongly affects complexity of grain boundaries, even after high temperature annealing
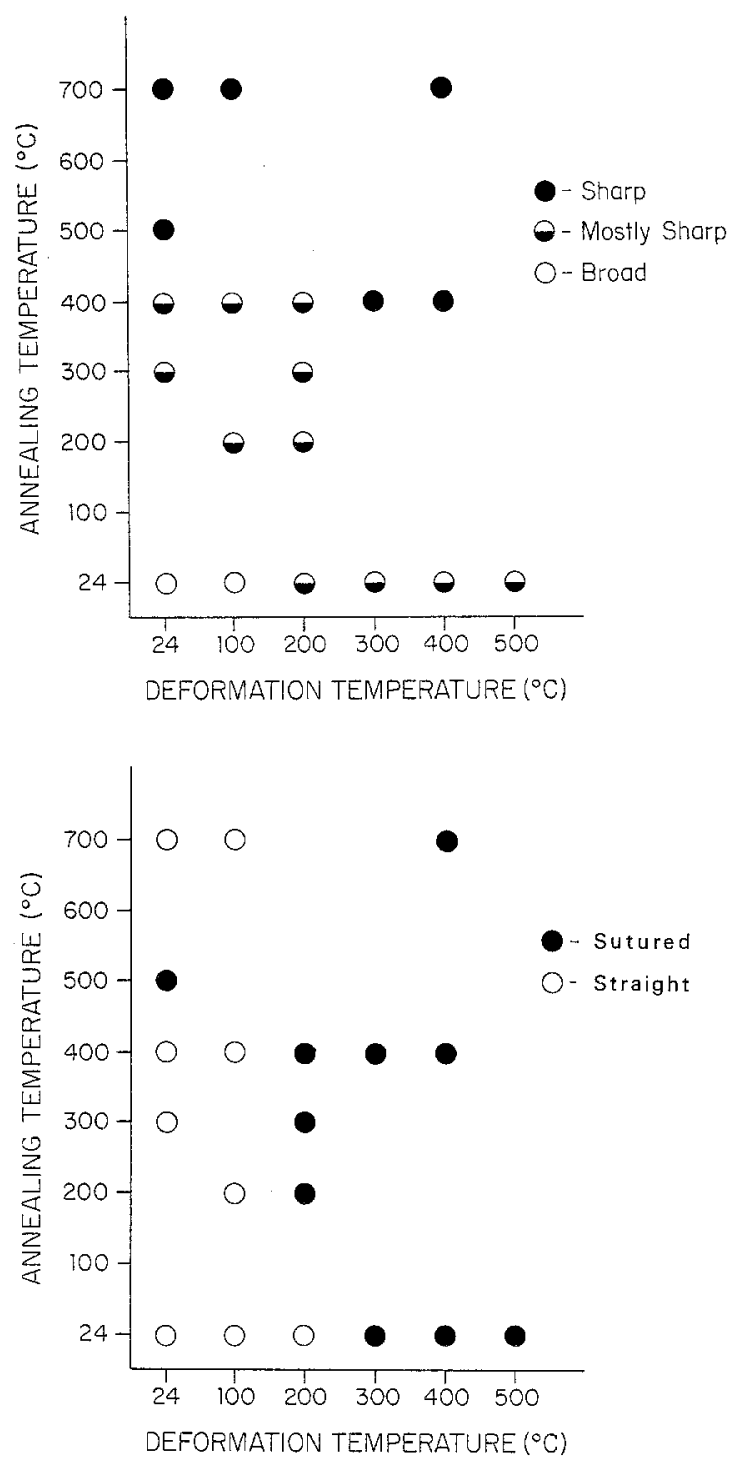

boundaries. New grains are quite equidimensional, and triple junctions are well equilibrated.

Two theories have been proposed for the mechanism by which new grains form from subgrains. Cahn (1950) argued that individual subgrains grow at the expense of their neighbors by migration of the subgrain boundaries, until at a more distant subgrain the boundary has become a true high angle grain boundary. $\mathrm{Hu}$ (1962) suggestd that adjacent subgrains coalesce into a single larger individual by means of small rotations and the removal of the subboundaries between them. The resulting individual has become a grain as it is now rotated with respect to neighboring individuals. We have no optical evidence 


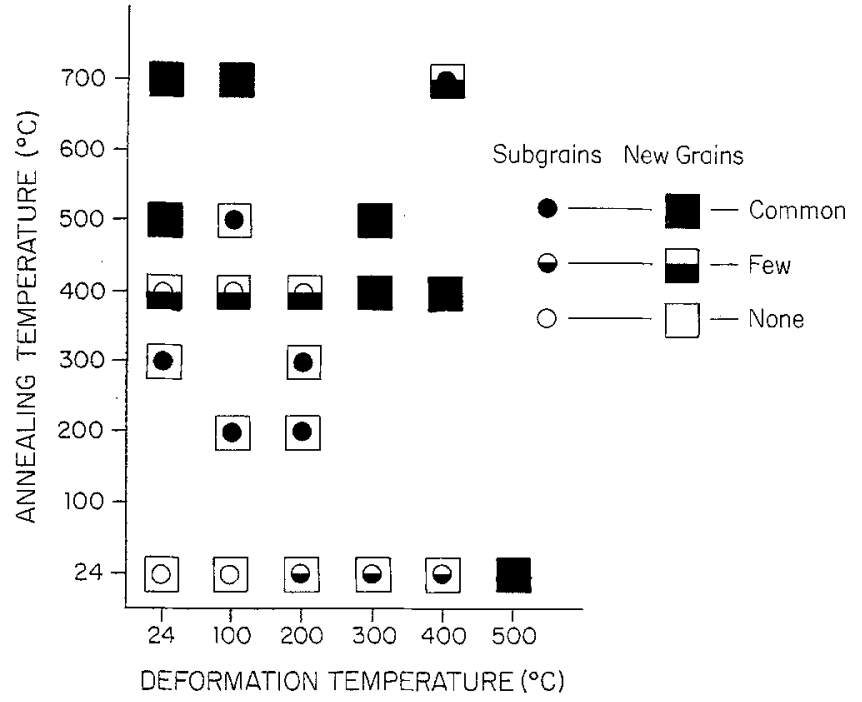

Fig. 5. Secondary subgrains and new grain mosaics as a function of deformation and annealing temperatures. Subgrains appear to grow into new grains as either deformation or annealing temperature is increased

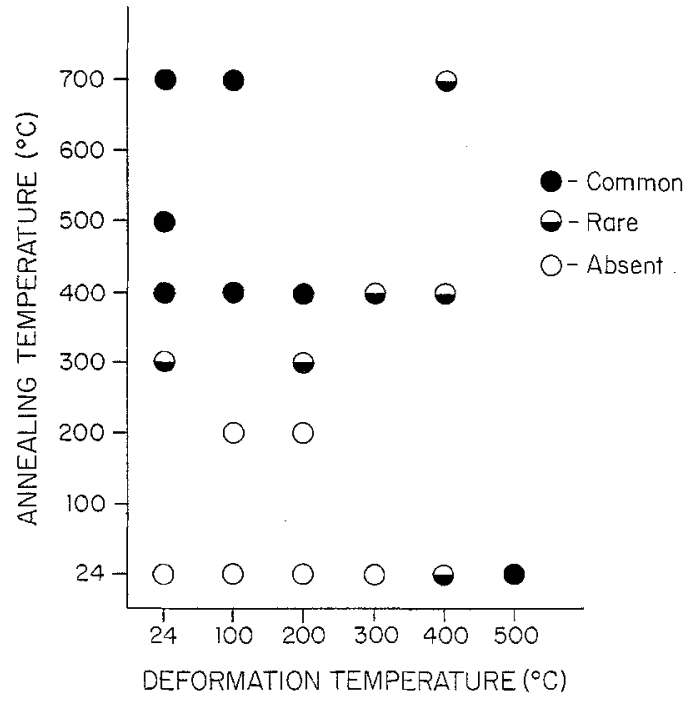

Fig. 6. Rapid grain boundary migration as a function of deformation and annealing temperatures. High deformation temperatures limit rapid grain boundary migration during annealing, due to "syntectonic" recovery and recrystallization. Low deformation temperatures allow massive grain growth to overwhelm original highly strained grains during annealing

favoring one or the other theory, but the evidence is strong that the mosaics do go through a stage as subgrains before becoming new grains separated by true grain boundaries.

New grain mosaics appear in the same samples as elongate grains. Few of the elongate grains appear to be replaced by new grain mosaics, and length: width ratios of 10 or more are still common locally. Both textural features appear to be reasonably stable unless annealing temperatures rise high enough to initiate rapid grain boundary migration. 
Fig. 7. Schematic illustration of reusable annealing chamber. The chamber can be evacuated but not to a high vacuum. When sealed, oxidation is virtually eliminated but no effort was made to control sulfur vapor pressure

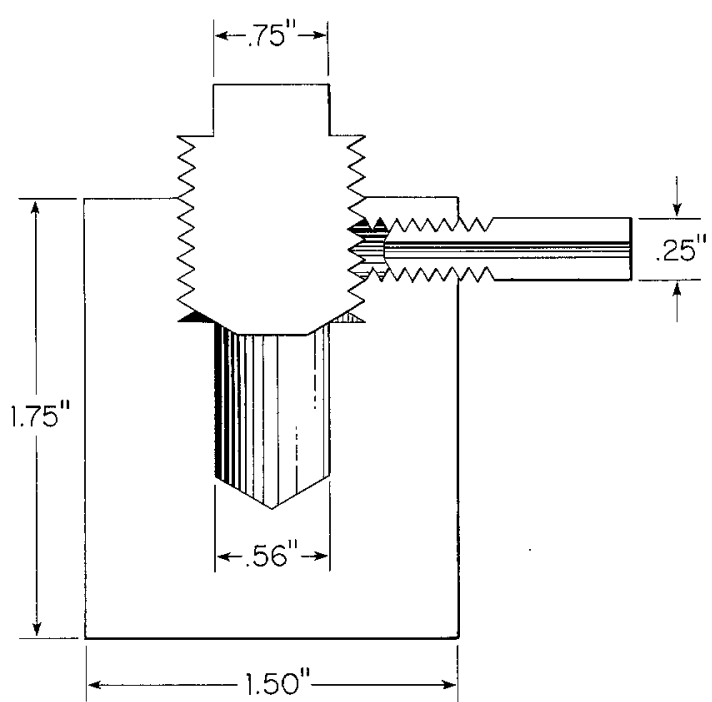

We saw little optical evidence for the type of nucleation and grain growth described by Siemes (1976, p. 767), except in runs similar to his in which the annealing temperature is high and the deformation temperature quite low. The more "natural" situation is for new grains to evolve from subgrains, which would correlate well with Siemes' (1964) annealing results on natural galena.

Rapid Grain Boundary Migration. The effectiveness of rapid grain boundary migration during annealing is highly dependent upon the original deformation history of the sample (Fig. 6). Grain boundary migration is a primary recrystallization process in which some grains grow very rapidly at the expense of highly deformed neighbors by simply moving the grain boundary outward and adding all of the material behind the migrating boundary to the growing grain. The formation of an unstrained grain from strained grains releases a substantial amount of stored elastic strain energy. Our experimental annealing results demonstrate just how important this stored strain energy is.

Grain boundary migration is easily recognized in the annealed samples by bulged simple grain boundaries, generally convex in the direction in which the boundary is migrating (Figs. $1 \mathrm{G}$ and $\mathrm{H} ; 2 \mathrm{~B}$ and $\mathrm{F}$ ). The boundary may be pinned locally by impurities, and may follow old cleavages or growth lines in the grain that is being destroyed. Generally there is no visible structure within the newly grown grain, and the original position of the boundary is seldom obvious. We recognized no precursors to the migration, either in the form of subgrains or "nuclei".

Not surprisingly the samples deformed at low temperatures and annealed at high temperatures were far more susceptible to rapid grain boundary migration than the samples in which some "syntectonic" recovery or recrystallization could occur during deformation (i.e., deformed at high temperatures; Fig. 6). In the samples deformed at low temperatures, significant migration could be 
seen in newly formed grains annealed at temperatures as low as $200^{\circ} \mathrm{C}$. After annealing for only six days at $700^{\circ} \mathrm{C}$, some grains had grown to be more than a millimeter across. In samples in which either elongate grains or new grain mosaics already existed, the degree and the rate of migration were both substantially reduced.

The grain boundary migration textures produced by experimental annealing are not equilibrium textures. This is clearly one very effective way to produce a much coarser grain size in galena during metamorphism whereas the new grain mosaics and elongate grains tend to reduce the average grain size of the sample. However, a more important effect of rapid grain boundary migration is to erase all previous textures. Fortunately, the process is most active when a highly deformed low temperature sample is subjected to very high temperatures of annealing and natural settings where this has been the case must be fairly rare.

\section{Discussion}

The observations of annealing behavior in galena are entirely compatible with prevailing views of recrystallization behavior in metals. In addition, the results have some important implications for the tectonic interpretation of recrystallized galena ore.

\section{Controls of Recrystallization}

Thanks largely to the pioneering work of metallurgists in the past three decades, and with the aid of high resolution transmission electron microscopy, the general outline of recrystallization processes is now reasonably well understood (Cahn, 1954, 1971; Beck and $\mathrm{Hu}, 1965)$. Several factors control the growth of new grains from a matrix of old grains of the same composition. Among these are the absolute temperature of annealing, the length of time of annealing, the degree to which the grains have recovered during and after deformation, the size of original grains, the complexity of grain boundaries, the orientation of the grains with respect to each other and to any deforming forces, and the character of defects within grains.

Results from our studies of several sulfide minerals (Clark and Kelly, 1973; Salmon et al., 1974; Kelly and Clark, 1975) show the strong dependence of annealing behavior on the character of the defects present in the individual mineral species. Galena shows clear recovery features over a range of deformation and annealing temperatures, whereas sphalerite and chalcopyrite do not. The behavior correlates well with the presence or absence of mobile dislocations in the deformed crystals. In galena, the dislocations are complete dislocations (the Burgers vector is equal to an identity period of the lattice) and can move through the crystal without disturbing its atomic structure. In sphalerite and chalcopyrite, dislocations tend to separate into partial dislocations in which 
the individual Burgers vectors are not an identity period of the lattice and a "stacking fault" forms between the partials. The formation of partials limits the ability of the dislocation to climb through the crystal and thus tends to inhibit recovery (Barrett and Massalski, 1967). Sphalerite and chalcopyrite deformed in the laboratory at temperatures as high as $500^{\circ} \mathrm{C}$ do not show any evidence of recovery. In annealing experiments and field examples, these two minerals appear either as highly deformed, unrecovered grains or a finegrained mosaic of completely recrystallized grains; commonly both textures appear in the same polished section. The lack of a recovery stage is a result of dislocation movements being so sluggish that recrystallization (nucleation and grain boundary migration) actually requires less energy to proceed than recovery.

All of the features observed in annealed galena constitute a part of continuum of textural or structural changes grading from recovery through bona fide recrystallization. The appearance of subgrains and the sharpening of kink band boundaries are both best described as recovery processes in which stored strain energy is released but grain boundaries remain more or less in their original positions. On the other hand, development of sutured kink band boundaries, true elongate grains, new grain mosaics, and large rapidly growing new grains are primary recrystallization processes involving the formation and migration of true grain boundaries (Beck, 1954). Evidence for several different processes appears simultaneously in most of our annealed galena samples, and we emphasize that our results strongly support the view that a "recrystallized texture" is the sum of overlapping and competing individual recovery and grain boundary migration processes.

\section{Tectonic Interpretation of Galena Textures}

The sulfide minerals in general, and galena in particular, may contain a record of the diagenetic or low-grade metamorphic conditions in which deformation took place. The thermal environments which sulfide textures may record are far below those to which the silicates are sensitive, and thus the textures may be extremely useful in deciphering the tectonic history of structures formed at shallow depths, such as slaty cleavage, cataclastic rocks in fault zones, concentric folds in sediments and contact metamorphism of deformed sediments. While we still do not have a quantitative fix on absolute temperatures in nature from the laboratory experiments, we can recognize qualitative progressions of textures through both deformation and later annealing events on the basis of grain shapes, the types of grain boundaries, and the degree of grain boundary migration. Furthermore, the laboratory data give us maximum temperatures for the survival of various deformation and recovery features, and can thus be helpful in interpreting the relationship between deformation and metamorphism in rocks bearing even small amounts of galena.

We can briefly review the approaches that appear to offer useful information from galena textures: 
1. Types and Orientations of Deformation Features. These include preferred orientations of kink bands, and of open cleavage fractures produced during the kinking operation (Salmon et al., 1974; Atkinson, 1974, 1976a and b). These features were shown to give approximate orientations of principal strains, at least during uncomplicated strain events. Furthermore, the presence of open cleavage fractures appears to be limited to low tectonic confining pressures and suggests "shallow" depths of burial. True cataclasis is limited to very shallow deformation at high strain rates, and the presence of twins suggests shocked galena (Lyall, 1967).

2. Types of Kink Band Boundaries. The kink bands formed during deformation fairly quickly convert to grain boundaries during recovery. However, the character of the grain boundaries depends on the temperature of deformation. If the rock is deformed at low temperatures, the kink band boundaries tend to be straight, even after a later high temperature anneal. If the rock is deformed at higher temperatures it undergoes syntectonic recrystallization and kink band boundaries (now converted to grain boundaries) tend to be sutured. These boundaries are little affected by later annealing. The distinction between "low" and "high" temperature is approximately $200^{\circ} \mathrm{C}$ in the laboratory but is likely to be somewhat lower under natural conditions of very low deformation rates.

3. Average Vickers Hardness as a Measure of Recovery. Two reductions in hardness may be present during annealing, the first associated with a recovery step and the second with true recrystallization (Stanton and Willey, 1970, 1071). The hardness of galena is also a function of grain orientation and possibly impurity content (Pauly and Siemes, 1973; Siemes, 1976) so a statistically significant number of hardness tests should be made, and care should be taken to consider the role of preferred orientations and galena composition in interpreting the results.

4. Evidence for Very Rapid Grain Boundary Migration. This behavior is favored by low temperature deformation followed by high temperature annealing. A possible natural setting might be a contact metamorphic zone in which deformed sediments are subjected to a local high heat flux, or a fault zone in which galena is sheared and subsequently rapidly heated by released regional strain energy.

The highly foliated schistose galena of the Coeur d'Alene district is a good example of the application of experimental behavior to a field problem. The foliation consists of elongate grains of galena. Stanton and Willey (1972) measured Vickers hardness levels and concluded that the galena had undergone both a deformation phase and a subsequent recovery phase. Salmon et al. (1974) showed that the distribution of open cleavage cracks established that the texture was the result of kinking and that the deformation probably occurred at shallow depth. From the present study we infer that the sutured boundaries on the elongate grains indicate syntectonic recovery and that no further annealing event is likely. 
A final caveat should be declared to curb indiscriminate use of these textural approaches to solving tectonic problems. The laboratory experiments are imperfect models of natural settings, greatly simplified chemically and highly telescoped in time. We believe that laboratory temperatures are maximum values, and that the same reactions may take place at somewhat lower temperatures in nature. Independent temperature estimates can and should be obtained from mineral reactions, fluid inclusions, fission track annealing, etc. However, from experimental work at several laboratories, we now have a reasonable outline of how galena textures are affected by both deformation and annealing. We contend that textural studies can yield an important line of evidence about the relative ages and environments of tectonic events, and that valuable limits can be placed on the strain history of rocks containing galena if this mineral is merely consulted in the course of one's tectonic studies.

\section{Appendix: Experimental Procedure}

Samples used in the annealing runs were segments of the cores which had been deformed at temperatures to $500^{\circ} \mathrm{C}$ and pressures to $2000^{\circ} \mathrm{C}$ bars by Salmon et al. (1974) in a high pressure deformation apparatus described by Clark and Kelly (1973). Briefly, the apparatus is an internally heated compression chamber in which the hydrostatic confining pressure is applied by pressurized argon gas and an additional compressive force is applied along the long axis of the sample by a hydraulically or mechanically driven piston. The temperature, confining pressure, and amount of total strain induced on the samples were accurately regulated and recorded.

Appropriate samples were chosen such that the effect of total strain, deformation temperature, and annealing temperature on the annealing textures in galena could be studied systematically. Portions of each sample were impregnated in cold-setting epoxy under vacuum, then polished by hand in 5 stages: 600 grit paper for a duration sufficient for the removal of the surface layer of the epoxy, 6 micron and 3 micron diamond polishing compounds, then 3 micron alpha and 0.05 micron gamma alumina micropolishes. The most important stage of the polishing was the 0.3 micron microwash stage, which if given sufficient time $(2 \mathrm{~min}$ ) was usually successful in removing the Bielby layer. This layer is the result of the rougher grinding and polishing operations which cause a large number of dislocations to concentrate near the polished surface. When the Bielby layer was not sufficiently removed before etching, the samples developed deeply pitted surfaces that obscured the features to be studied.

In preliminary studies, the etching technique of Brebrick and Scanlon (1957) was utilized. The etching solution consisted of one part concentrated hydrochloric acid with three parts dilute $(100 \mathrm{gm} / \mathrm{l})$ thiourea. The solution was used at a temperature of $60^{\circ} \mathrm{C}\left( \pm 2^{\circ} \mathrm{C}\right)$ for a period of 5 to $60 \mathrm{~s}$. However, the technique proved unacceptable on samples deformed or annealed at or above $300^{\circ} \mathrm{C}$. Such samples developed deeply pitted surfaces even if etched for only short intervals of time $(5 \mathrm{~s})$. The problem was solved by using the same reagents in different proportions at slightly lower temperatures. A mixture of 1 part concentrated hydrochloric acid and 6 parts dilute $(100 \mathrm{gm} / 1)$ thiourea used at $50^{\circ}$ to $55^{\circ} \mathrm{C}$ produced acceptable results on all samples. A fresh solution was required for each sample. Most samples etched to the correct intensity between 1 and $4 \mathrm{~min}$. Because of the relatively slow rate of etching, we had considerable control over the degree to which each sample was etched.

Samples with one surface already polished and etched were then sealed into evacuated annealing chambers in preparation for further annealing. In order to avoid the costs and time involved in the conventional use of vycor or pyrex tubing, an annealing chamber made of $99+\%$ aluminum was designed (Fig. 7). Aluminum was chosen because of its inertness in the presence of sulfur vapor. The advantages of the chamber were that it could be used repeatedly and was more easily evacuated than glass. The disadvantage was that threads wore quickly and the cone seal was easily damaged. Inert alloys would probably give even better service. 
The samples, wrapped in aluminum foil, were placed in individual chambers and the chambers were evacuated as the cap, sealed around its top threads with teflon tape and modeling clay, was screwed on. This proved to be a reasonably airtight system and the amount of oxidation which took place was negligible. No effort was made to control the sulfur vapor pressure closely. A few grams of ground galena were added to the chamber to reduce sample oxidation even further. The aliminum chambers were used for all samples annealed below $700^{\circ} \mathrm{C}$. The samples annealed at $700^{\circ} \mathrm{C}$ were placed in Vycor tubing, since the melting point of aluminum is $660^{\circ} \mathrm{C}$.

The ovens were preheated to the desired temperatures prior to placing the samples within them. Samples annealed at $200^{\circ} \mathrm{C}$ were heated for 50 days, those at $300^{\circ} \mathrm{C}$ for 40 days, those at $400^{\circ} \mathrm{C}$ for 40 days, those at $500^{\circ} \mathrm{C}$ for 30 days, and those at $700^{\circ} \mathrm{C}$ for 6 days. A sample's progress was checked each day for the first two days, every two days for the following eight days, and an average of every six days thereafter.

The samples were observed in reflected light before and after deformation in order to determine the extent of syntectonic annealing. Upon removal from the ovens the samples were reimpregnated, lightly repolished, etched and again studied optically with reflected light. The minimal amount of cold-setting epoxy used to eliminate plucking during polishing had little effect on the sample surfaces during annealing.

\section{References}

Aktinson, B.K. : Experimental deformation of polycrystalline galena, chalcopyrite, and pyrrhotite. Trans, Inst. Mining Met. B83, 19-28 (1974)

Atkinson, B.K.: Deformation mechanism maps for polycrystalline galena. Earth Planet. Sci. Lett. 29, 210-218 (1976a)

Atkinson, B.K.: The temperature and strain rate dependent mechanical behavior of polycrystalline galena ore. Econ. Geol. 71, 513-525 (1976b)

Barrett, C.S., Massalski, T.B.: Structure of metals. 654 p. New York: McGraw-Hill 1966

Beck, P.A.: Annealing of cold worked metals. Advan. Phys. 3, 245-325 (1954)

Beck, P.A., Hu, H.: The origin of recrystallization textures. In: Recrystallization, grain growth, and textures, pp. 393-431. Am. Soc. Metals (1965)

Brebrick, R.F., Scanlon, W.W.: Chemical etches and etch pit patterns on PbS crystals. J. Chem. Phys. 27, 607-608 (1957)

Cahn, R.W.: A new theory of recrystallization nuclei. Proc. Phys. Soc. (London) A63, 323-336 (1950)

Cahn, R.W.: Recovery and recrystallization. In: Physical metallurgy (R.W. Cahn, ed.), pp. 1129-1198. Amsterdam: North-Holland Publishing Co. 1971

Carter, N.L.: Steady state flow of rocks. Reviews of Geophysics and Space Physics 14, 301-360 (1976)

Clark, B.R., Kelly, W.C.: Sulfide deformation studies: I. Experimental deformation of pyrrhotite and sphalerite to 2000 bars and $500^{\circ}$ C. Econ. Geol. 68, 332-352 (1973)

Griggs, D.T., Paterson, M.S., Heard, H.C., Turner, F.J.: Annealing recrystallization in calcite crystals and aggregates. In: Geol. Soc. Am. Mem. 79, 21-38 (1960)

Hobbs, B.E.: Recrystallization of single crystals of quartz. Tectonophysics 6, 353-401 (1968)

$\mathrm{Hu}, \mathrm{H}$. : Direct observations on the annealing of a Si-Fe crystal in the electron microscope. Trans. Am. Inst. Min. Met. Pet. Eng. 224, 75-84 (1963)

Kelly, W.C., Clark, B.R. : Sulfide deformation studies: III. Experimental deformation of chalcopyrite to 2000 bars and $500^{\circ} \mathrm{C}$. Econ. Geol. 60, 431-453 (1975)

Lyall, K.D.: The origin of mechanical twinning in galena. Am. Mineralogist 51, $243-247$ (1966)

Lyall, K.D., Paterson, M.S. : Plastic deformation of galena. Acta Met. 14, 371-383 (1966)

Pauly, H., Siemes, H. : Microhardness of galena related to Ag-Bi-content, orientation and deformation. Bull. Geol. Soc. Denmark 22, $50-78$ (1973)

Salmon, B.C., Clark, B.R., Kelly, W.C.: Sulfide deformation studies: II. Experimental deformation of galena to 2000 bars and $400^{\circ} \mathrm{C}$. Econ. Geol. 69, 1-16 (1974)

Siemes, H.: Zum Rekristallisationsverhalten von natürlich verformten Bleiglanzen. Neues Jb. Mineral. Abhandl. 102, 1-30 (1964) 
Siemes, H.: Recovery and recrystallization of experimentally deformed galena. Econ. Geol. 71, 763-771 (1976)

Stanton, R.L.: Ore petrology. New York: McGraw-Hill 1972

Stanton, R.L., Gorman, H.: A phenomenological study of grain boundary migration in some common sulfides. Econ. Geol. 63, 907-923 (1968)

Stanton, R.L., Gorman-Willey, H. : Natural work-hardening in galena, and its experimental reduction. Econ. Geol. 65, 182-194 (1970)

Stanton, R.L., Willey, H.G.: Recrystallization softening and hardening in sphalerite and galena. Econ. Geol. 66, 1232-1238 (1971)

Stanton, R.L., Willey, H.G.: Experiments on a specimen of galena ore from Coeur d'Alene, Idaho, Econ. Geol. 67, 776-778 (1972)

Received May 5, 1977 / Accepted June 15, 1977 